\title{
Synthesis of Mn-Doped ZnSe-ZnS Alloy Quantum Dots by a Hydrothermal Method
}

\section{Hisaaki Nishimura, Yuxin Lin, Masayuki Hizume, Taichi Taniguchi, Naoteru Shigekawa, Tomomi Takagi, Susumu Sobue, Shoichi Kawai, Eiichi Okuno, DaeGwi Kim}

\begin{tabular}{|c|l|}
\hline Citation & Chemistry Letters. 48(9); 1081-1083 \\
\hline Issue Date & $2019-06-15$ \\
\hline Type & Journal Article \\
\hline Textversion & Author \\
\hline Rights & $\begin{array}{l}\text { C } 2019 \text { The Chemical Society of Japan. The following article has been accepted by } \\
\text { Chemistry Letters. After it is published, it will be found at https://doi.org/10.1246/cl.190365. }\end{array}$ \\
\hline $\begin{array}{c}\text { Supporting } \\
\text { Information }\end{array}$ & Supporting Information is available on https://doi.org/10.1246/cl.190365. \\
\hline DOI & $10.1246 / c l .190365$ \\
\hline
\end{tabular}

Self-Archiving by Author(s) Placed on: Osaka City University 


\title{
Synthesis of Mn-Doped ZnSe-ZnS Alloy Quantum Dots by a Hydrothermal Method
}

\author{
Hisaaki Nishimura, ${ }^{1}$ Yuxin Lin, ${ }^{1}$ Masayuki Hizume, ${ }^{1}$ Taichi Taniguchi,${ }^{1}$ Naoteru Shigekawa,${ }^{1}$ Tomomi Takagi, ${ }^{2}$ Susumu Sobue,${ }^{2}$ Shoichi \\ Kawai, ${ }^{2}$ Eiichi Okuno, ${ }^{2}$ and DaeGwi Kim ${ }^{1, *}$ \\ ${ }^{1}$ Department of Applied Physics, Graduate School of Engineering, Osaka City University, \\ 3-3-138, Sugimoto, Sumiyoshi-ku, Osaka 558-8585, Japan \\ ${ }^{2}$ Advanced Research and Innovation Center, DENSO CORPORATION, \\ 500-1, Minamiyama, Komenoki-cho, Nisshin-shi, Aichi 470-0111, Japan
}

\section{(Received $<$ Month $><$ Date $>$, $<$ Year $>$; CL- $<$ No $>$; E-mail: $<$ tegi@a-phys.eng.osaka-cu.ac.jp $>$ )}

This study aims to report the hydrothermal synthesis of water-soluble Mn-doped ZnSe-ZnS alloy quantum dots (QDs), wherein manganese $\left(\mathrm{Mn}^{2+}\right)$ serves as an emission center. The alloy composition was controlled by the mixing ratio of ZnSe:Mn and ZnS:Mn precursor solutions. The photoluminescence (PL) band originating from the $d-d$ transition in $\mathrm{Mn}^{2+}$ was clearly observed. With an increase in the amount of $\mathrm{ZnS}$ in the alloy QDs, the absorption onset energy shifted toward higher energy, demonstrating the successful preparation of alloy QDs, and Mn PL intensity increased as well.

The energy limitation should be overcome for the realization of a sustainable society. Power generation using solar cells is important to achieve renewable energy. Among solar cells, silicon (Si)-type solar cells are the most widespread. While Si-type solar cells effectively use light in the visible to near-infrared region for photoelectric conversion, their spectral sensitivity to ultraviolet light is low. Recently, wavelength conversion materials those convert ultraviolet light to visible light have been developed to improve the photoelectric conversion efficiency of Si-type solar cells [1-6].

$\mathrm{Mn}^{2+}$-doped $\mathrm{ZnSe}$ quantum dots (QDs) show potential as a wavelength conversion material because $\mathrm{ZnSe}$ absorbs light in the blue to ultraviolet region [7-9] and exhibits orange emission as a result of the $d$ - $d$ transition in the emission center of $\mathrm{Mn}^{2+}$ [10-13]. In our previous study, we reported the hydrothermal synthesis of water-soluble ZnSe:Mn QDs with a photoluminescence (PL) quantum yield of $20 \%$ under optimal conditions [13]. The PL quantum yield was further increased to $30 \%$ by preparing $\mathrm{ZnSe}: \mathrm{Mn} / \mathrm{ZnS}$ core/shell QDs. However, although the absorption onset energy of hydrothermally prepared ZnSe:Mn QDs shifts toward lower energy with an increase in the reaction time (i.e., as the mean QD diameter increases), the Mn PL intensity also depends strongly on reaction time. Therefore, since $\mathrm{ZnSe}$ Mn QDs synthesized for a specific time $(15 \mathrm{~min})$ exhibit the maximum $\mathrm{Mn}$ PL intensity, it is difficult to control the absorption onset energy by modulating the QD diameter while maintaining a high Mn PL intensity.

This study focuses on $\mathrm{Mn}^{2+}$-doped $\mathrm{ZnSeS}$ QDs, which are alloy semiconductors of $\mathrm{ZnSe}$ and $\mathrm{ZnS}$. The bandgap energies of alloy semiconductors can be controlled over a wide range by changing the alloy composition [14-18]. Thus, ZnSeS:Mn QDs have the potential to exhibit high Mn PL intensity along with controlled absorption energy based on the alloy composition.
Herein, ZnSeS:Mn QDs were hydrothermally synthesized as follows. First, two precursor solutions of $\mathrm{ZnSe}: \mathrm{Mn}$ and $\mathrm{ZnS}: \mathrm{Mn}$ were separately prepared via a procedure similar a previous study [13]. Briefly, $\mathrm{Zn}\left(\mathrm{ClO}_{4}\right)_{2} \cdot 6 \mathrm{H}_{2} \mathrm{O}(1.0 \mathrm{mmol}), N$-acetyl- $L$-cysteine $(4.8 \mathrm{mmol})$ as a ligand, and $\mathrm{Mn}\left(\mathrm{ClO}_{4}\right)_{2} \cdot 6 \mathrm{H}_{2} \mathrm{O}(0.02 \mathrm{mmol})$ were dissolved in $50 \mathrm{~mL}$ deionized water. The $\mathrm{pH}$ of the aqueous solution was then adjusted to a $\mathrm{pH}$ of 8.5 (5.0), and a freshly prepared solution of $\mathrm{NaHSe}\left(\mathrm{Na}_{2} \mathrm{~S} ; 0.2 \mathrm{mmol}\right)$ was added to prepare the ZnSe:Mn (ZnS:Mn) precursor solution. Subsequently, the $\mathrm{pH}$ of each precursor solution was adjusted to 10.0. $\mathrm{ZnSe}_{x^{\prime}} \mathrm{S}_{1-x^{\prime}}: \mathrm{Mn}$ precursor solution was prepared by mixing the $\mathrm{ZnSe}: \mathrm{Mn}$ and $\mathrm{ZnS}: \mathrm{Mn}$ precursor solutions, where $x^{\prime}$ denotes the mixing ratio of two precursor solutions. Finally, $10 \mathrm{~mL}$ of the precursor solution was loaded into a glass reactor (autoclave) and
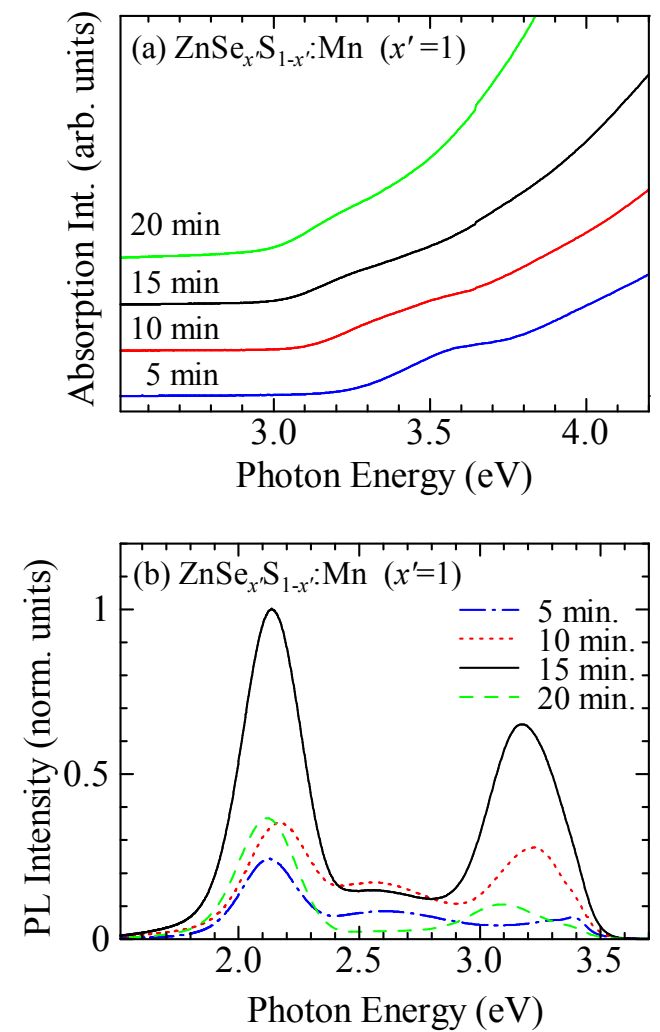

Figure 1. (a) Absorption and (b) PL spectra of ZnSe:Mn QDs synthesized with reaction times of 5, 10, 15, and 20 $\min$. 
incubated at $200{ }^{\circ} \mathrm{C}$ for a specified period and then cooled down to room temperature. All reaction solutions were used for various measurements without further purification.

The absorption and PL spectra of the sample solutions were recorded using a JASCO V-650 ultraviolet/visible spectrophotometer and JASCO FP-8300 spectrofluorometer, respectively. The excitation wavelength was fixed at $325 \mathrm{~nm}$. The PL intensity of each sample was compared by dividing the PL intensity by the absorption intensity at the excitation wavelength. X-ray diffraction (XRD) spectra were collected using a Rigaku SmartLab diffractometer equipped with a $\mathrm{Cu}$ $\mathrm{K} \alpha$ radiation source $(\lambda=0.154 \mathrm{~nm})$.

Figure 1 shows the absorption and PL spectra of ZnSe:Mn QDs $\left(x^{\prime}=1\right)$ synthesized from the ZnSe:Mn precursor solution for reaction times of 5, 10, 15, and $20 \mathrm{~min}$. In the absorption spectra, absorption structures are observed at energies above the bandgap energy of bulk $\mathrm{ZnSe}(2.7 \mathrm{eV})$, indicating the successful preparation of QDs. The PL spectra clearly show that the Mn PL intensity was maximized in the sample synthesized for $15 \mathrm{~min}$. As shown in Figures S2 and $\mathrm{S} 3$, the Mn PL intensities of $\mathrm{ZnSe}_{x^{\prime}} \mathrm{S}_{1-x^{\prime}}$ :Mn QDs, where $x^{\prime}=$ 0.6 and 0.8 , were also maximized at the reaction time of 15 $\min$.

Figure 2(a) shows the absorption spectra of $\mathrm{ZnSe}_{x^{\prime}} \mathrm{S}_{1-x^{\prime}}$ :Mn QDs, where $x^{\prime}=0.6,0.8$, and 1, synthesized with a reaction time of $15 \mathrm{~min}$. The absorption energy was shifted toward higher energy for $x^{\prime}=0.6$ and 0.8 , in
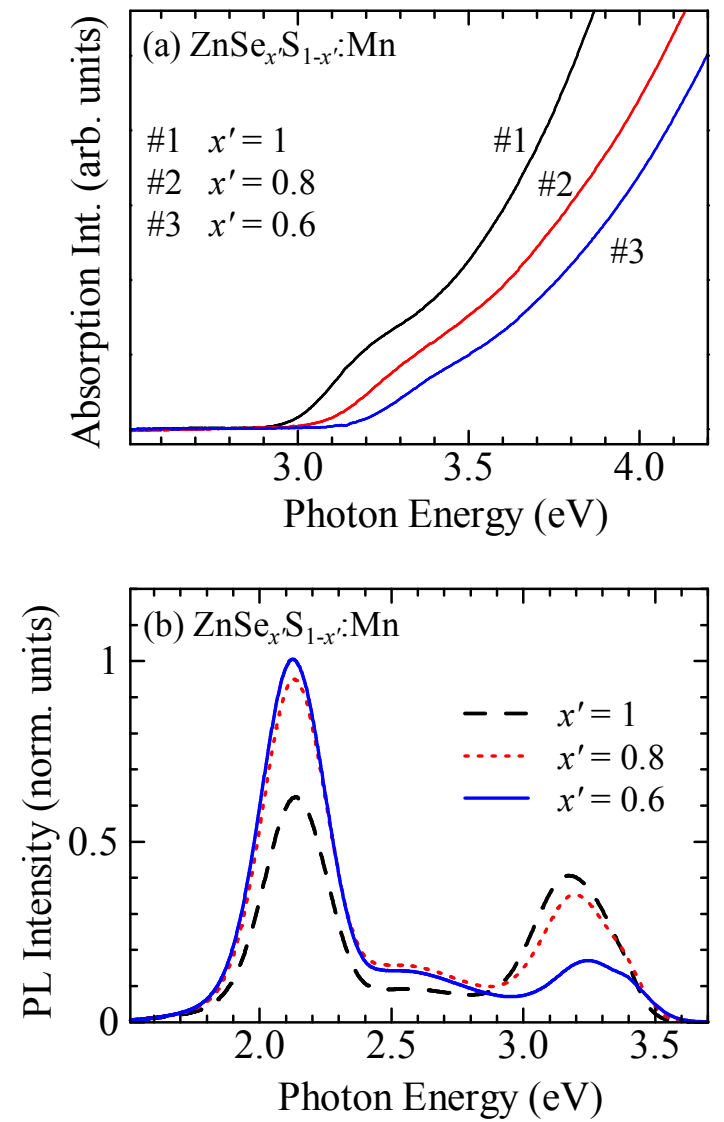

Figure 2. (a) Absorption and (b) PL spectra of $\mathrm{ZnSe}_{x^{\prime}} \mathrm{S}_{1-}$ $x^{\prime}$ :Mn QDs, where $x^{\prime}=0.6,0.8$, and 1 , synthesized with the reaction time of $15 \mathrm{~min}$.

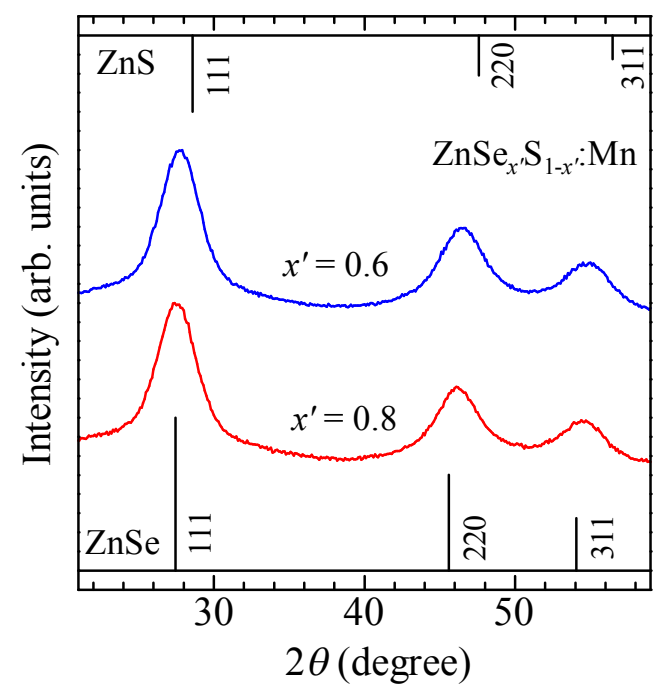

Figure 3. XRD patterns of $\mathrm{ZnSe}_{x^{\prime}} \mathrm{S}_{1-x^{\prime}}$ :Mn QDs, where $x^{\prime}=$ 0.6 and 0.8 (JCPDS Card No. 80-0021 for ZnSe and 050566 for $\mathrm{ZnS})$.

comparison with that for $x^{\prime}=1$, suggesting that the alloy composition of the QDs can be controlled by varying the mixing ratio of the $\mathrm{ZnS}: \mathrm{Mn}$ and $\mathrm{ZnSe}: \mathrm{Mn}$ precursor solutions. XRD was used to determine the alloy compositions of the ZnSeS:Mn QDs (Fig. 3). Three diffraction peaks corresponding to the (111), (220), (311) planes of the cubic zinc-blende structure were observed, and each peak is shifted toward higher angle with a decrease in $x^{\prime}$, again demonstrating the successful preparation of alloy ZnSeS QDs. For each QD sample, the lattice constant was calculated from the diffraction angle of the (111) plane using Bragg's law, and the actual alloy composition $(x)$ was estimated using Vegard's law. The alloy compositions of $\mathrm{ZnSe}_{x^{\prime}} \mathrm{S}_{1-x^{\prime}}: \mathrm{Mn}$ QDs for $x^{\prime}=$ 0.8 and 0.6 were determined to be $x=0.80$ and 0.64 , respectively. These results indicate that the alloy composition

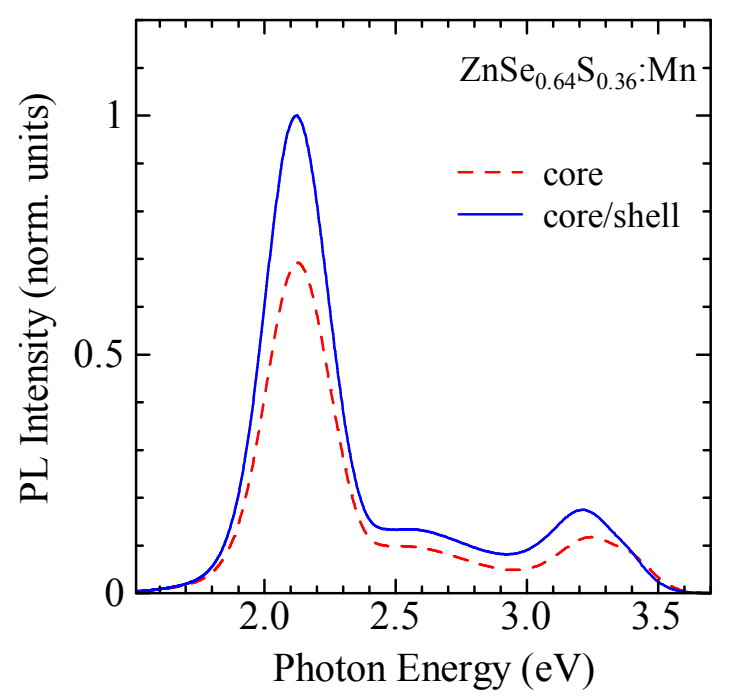

Figure 4. PL spectra of $\mathrm{ZnSe}_{0.64} \mathrm{~S}_{0.36}:$ Mn core QDs (dashed curve) and $\mathrm{ZnSe}_{0.64} \mathrm{~S}_{0.36}: \mathrm{Mn} / \mathrm{ZnS}$ core/shell QDs (solid curve). 
of the ZnSeS:Mn QDs can be controlled by altering the mixing ratio of the $\mathrm{ZnSe}: \mathrm{Mn}$ and $\mathrm{ZnS}: \mathrm{Mn}$ precursor solutions, and the absorption energy of the ZnSeS:Mn QDs can be controlled based on the alloy composition.

Figure 2(b) shows the PL spectra of the $\mathrm{ZnSe}_{x} \mathrm{~S}_{1-x}: \mathrm{Mn}$ QDs for $x=0.64,0.80$, and 1 . In the case where $x=0.80$ and 0.64 , the band edge PL energy is shifted toward higher energy in comparison to that in the ZnSe:Mn QDs. This phenomenon corresponds to an increase in the absorption energy with a decrease in $x$, as noted above when discussing Fig. 2(a). On the contrary, the PL of Mn is observed at approximately 2.1 $\mathrm{eV}$ for all alloy compositions since it originates from the $d$-d transition in the emission center of $\mathrm{Mn}^{2+}$ [10-12]. The intensity of the Mn PL increases with a decrease in $x$.

Finally, $\mathrm{ZnSe}_{0.64} \mathrm{~S}_{0.36}: \mathrm{Mn} / \mathrm{ZnS}$ core/shell QDs were prepared by covering the surfaces of the $\mathrm{ZnSe}_{0.64} \mathrm{~S}_{0.36}$ :Mn QDs, which exhibited the highest Mn PL intensity, with ZnS shell layers. The core/shell structure is expected to suppress nonradiative recombination on the surfaces of the QDs and enhance the PL intensity [19-21]. Figure 4 shows the PL spectra of the $\mathrm{ZnSe}_{0.64} \mathrm{~S}_{0.36}: \mathrm{Mn}$ core QDs, as shown by dashed curve, and the $\mathrm{ZnSe}_{0.64} \mathrm{~S}_{0.36}: \mathrm{Mn} / \mathrm{ZnS}$ core/shell QDs, as shown by solid curve. The Mn PL intensity of the $\mathrm{ZnSe}_{0.64} \mathrm{~S}_{0.36}: \mathrm{Mn} / \mathrm{ZnS}$ core/shell QDs was 1.4 times higher than that of the core QDs.

In summary, we hydrothermally synthesized Mn-doped alloy QDs wherein $\mathrm{Mn}^{2+}$ serves as the emission center to prepare QDs exhibiting high Mn PL intensity and controllable absorption energy based on the alloy composition. We successfully controlled the alloy composition in the $\mathrm{ZnSe}_{x} \mathrm{~S}_{1-x}: \mathrm{Mn}$ QDs and absorption energy by altering the mixing ratio of the $\mathrm{ZnSe}: \mathrm{Mn}$ and $\mathrm{ZnS}: \mathrm{Mn}$ precursor solutions. The Mn PL intensity increased with a decrease in $x$. Finally, the Mn PL intensity was increased by 1.4 times by coating the surfaces of $\mathrm{ZnSe}_{0.64} \mathrm{~S}_{0.36}: \mathrm{Mn}$ core QDs with $\mathrm{ZnS}$ shells to create $\mathrm{ZnSe}_{0.64} \mathrm{~S}_{0.36}: \mathrm{Mn} / \mathrm{ZnS}$ core/shell QDs.

N.S. and D.K. acknowledges a Grant-in-Aid for Scientific Research (B) (No. 17H03538) from the Japan Society for the Promotion of Science (KAKENHI). This work was also supported by JST OPERA Program (JPMJOP1843).

\section{References and Notes}

1 T. Trupke, M. A. Green, P. Würfel, J. Appl. Phys. 2002, 92, 1668.

2 B. S. Richards, Solar Energy Materials and Solar Cells 2006, 90 , 1189.

3 E. Klampaftis, D. Ross, K. R. Mclntosh, B. S. Richards, Sol. Energy Mater. Sol. Cells 2009, 93, 1182.

4 E. Klampaftis, B. S. Richards, Progress in Photovoltaics 2010, 19 345.

5 X. Pi, Q. Li, D. Li, D. Yang, Sol. Energy Mater. Sol. Cells 2011, 95, 2941.

6 D. -C. Cheng, H. -C. Hao, M. Zhang, W. Shi, M. Lu, Nanoscale Res. Lett. 2013, 8, 291.

7 D. Zhao, J.-H. Li, F. Gao, C. Zhang, Z. He, RSC Adv. 2014, 4, 47005.

8 Y-S. Lee, H-B. Bu, T. Taniguchi, T. Takagi, S. Sobue, H. Yamada, T. Iwaki, D. Kim, Chem. Lett. 2016, 45, 878.

9 Y.-S. Lee, K. Nakano, H-B. Bu, D. Kim, Appl. Phys. Express 2017, 10, 065001.

10 R. N. Bhargava, D. Gallagher, X. Hong, A. Nurmikko, Phys. Rev. Lett. 1994, 72, 416.
11 C. Gan, Y. Zhang, D. Battaglia, X. Peng, M. Xiao, Appl. Phys. Lett. 2008, 92, 241111.

12 R. Zeng, T. Zhang, G. Dai, B. Zou, J. Phys. Chem. C 2011, 115, 3005 .

13 H. Nishimura, Y. Lin, M. Hizume, T. Taniguchi, N. Shigekawa, T. Takagi, S. Sobue, S. Kawai, E. Okuno, D. Kim, AIP Advances 2019, 9, 025223.

14 K. Tomihira, D. Kim, M. Nakayama, J.Lumin. 2005, 112, 131.

15 D. Kim, A. Nabeshima, M. Nakayama, Jpn. J. Appl. Phys. 2005, $44,1514$.

16 M. W. DeGroot, H. Rösner, J. F. Corrigan, Chem. Eur. J. 2006, $12,1547$.

17 J. Cheng, D. Li, T. Cheng, B. Ren, G. Qang, J. Li, J. Alloy Com. 2014, 589,539 .

18 L. Jing, S. V. Kershaw, Y. Li, X. Huang, Y. Li, A. L. Rogach, M. Gao, Chem. Rev. 2016, 116, 10623.

19 B. O. Dabbousi, J. Rodriguez-Viejo, F. V. Mikulec, J. R. Heine, H. Mattoussi, R. Ober, K. F. Jensen, and M. G. Bawendi, J. Phys. Chem. B 1997, 101, 9463.

20 V. V. Nikesh, and S. Mahamuni, Semicond. Sci. Technol. 2001, $16,687$.

21 L. Li, A. Pandey, D. J. Werder, B. P. Khanal, J. M. Pietryga, and V. I. Klimov, J. Am. Chem. Soc. 2011, 133, 1176. 